Supporting Information

Antioxidant and myocardial preservation activities of natural phytochemicals from Mung Bean (Vigna

\title{
radiata $\mathbf{L}$.) seeds
}

Yan Bai*, Jiawei Chang*, Yan Xu*, Dan Cheng*, Hongxin Liu ${ }^{\dagger}$, Yunli Zhao*, Zhiguo $\mathrm{Yu}^{*}$

*Department of Pharmaceutical Analysis, School of Pharmacy, Shenyang Pharmaceutical University, Shenyang 110016, China

$\dagger$ Dalian Weida Pharmacy Co., Limited, 12-7 Zhuhai Street, Xigang District, Dalian 116011, China 


\section{Contents}

Figure S1. The UV spectrum of compound 1

Figure S2. The IR spectrum of compound 1

Figure S3. The FT-ICR-MS spectrum of compound 1

Figure S4. The ${ }^{1} \mathrm{H}-\mathrm{NMR}$ spectrum of compound 1

Figure S5. The ${ }^{13} \mathrm{C}-\mathrm{NMR}$ spectrum of compound $\mathbf{1}$

Figure S6. The HSQC spectrum of compound 1

Figure S7. The HMBC spectrum of compound 1 
Figure S1. The UV spectrum of compound 1

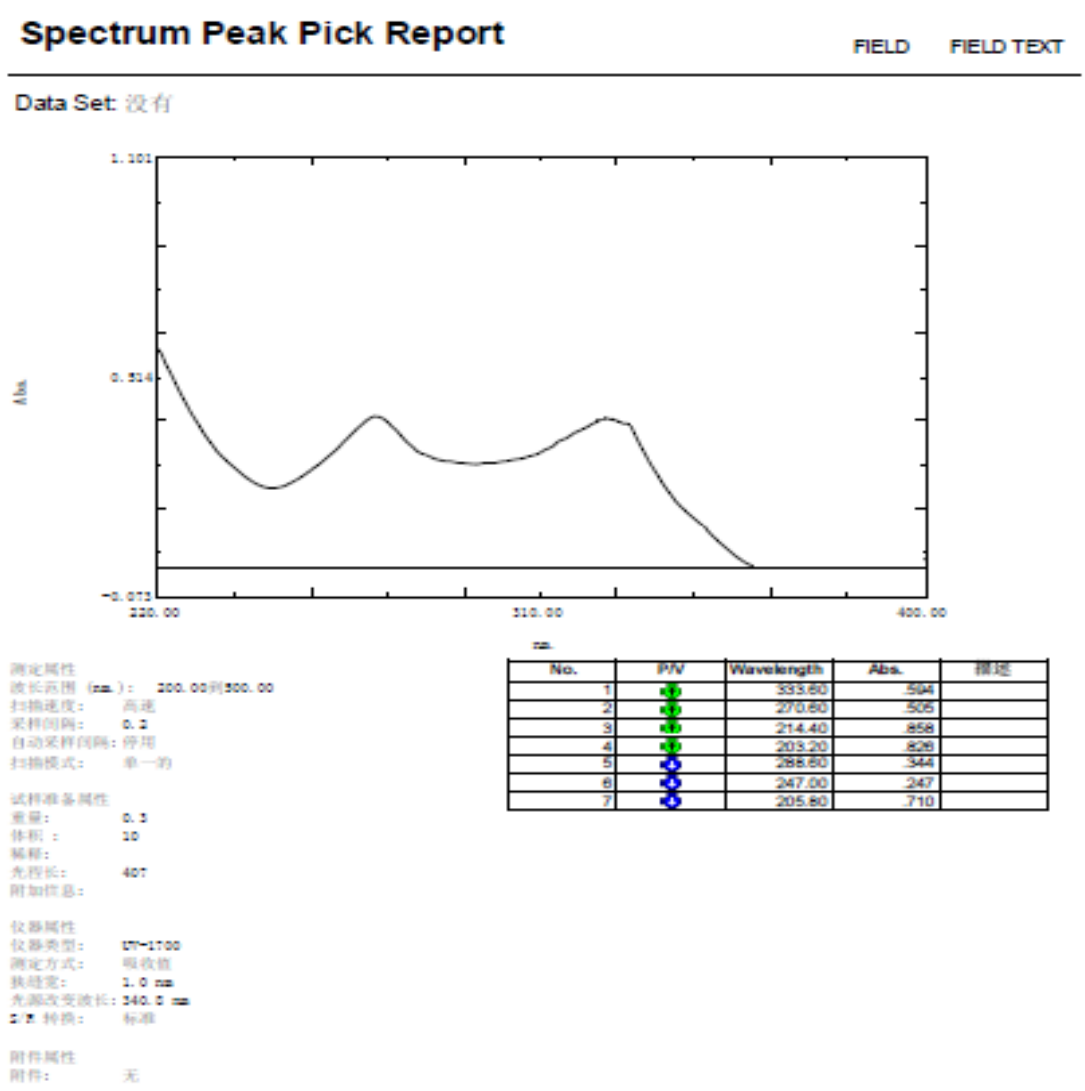

Figure S2. The IR spectrum of compound 1

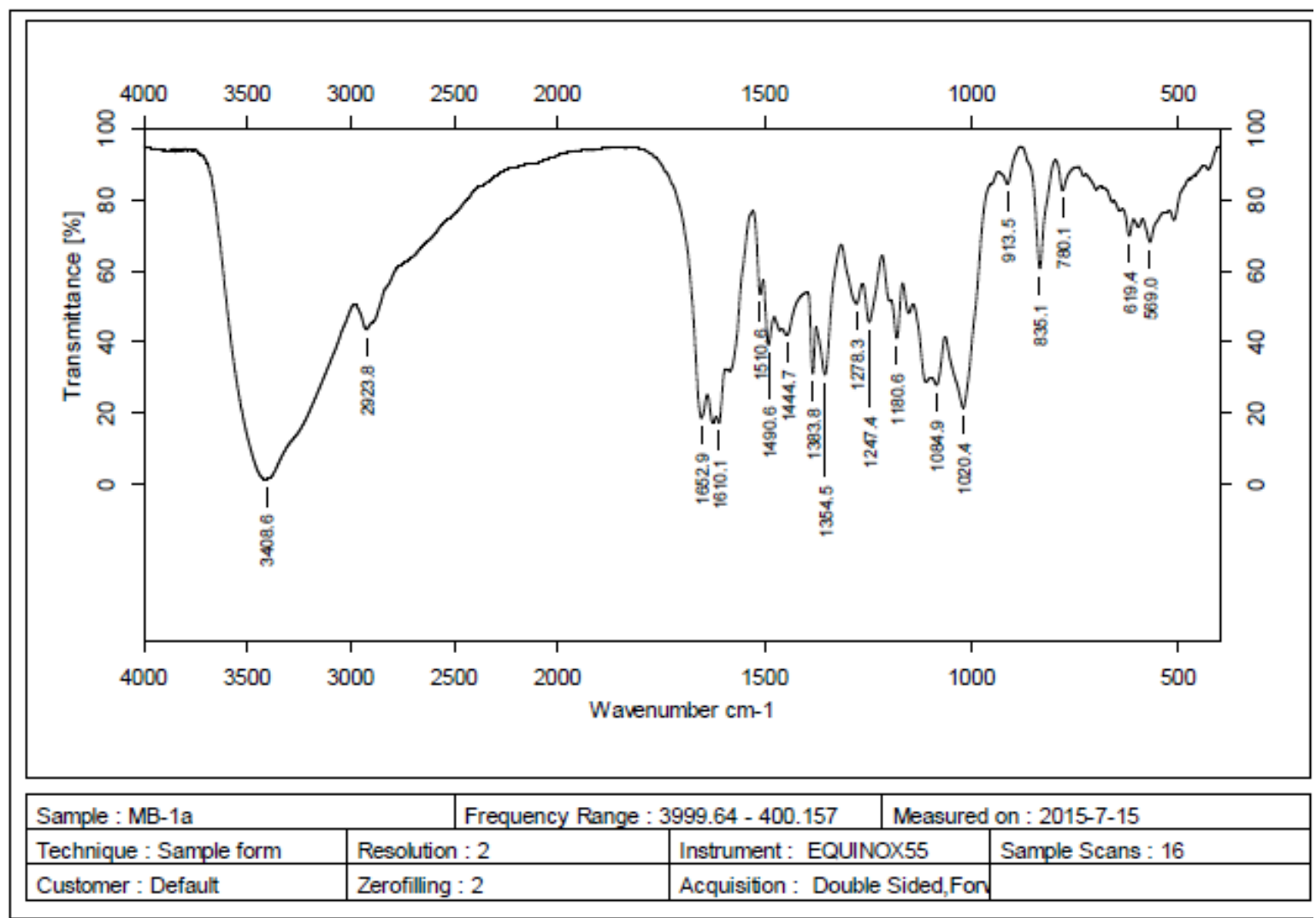


Figure S3. The FT-ICR-MS spectrum of compound 1

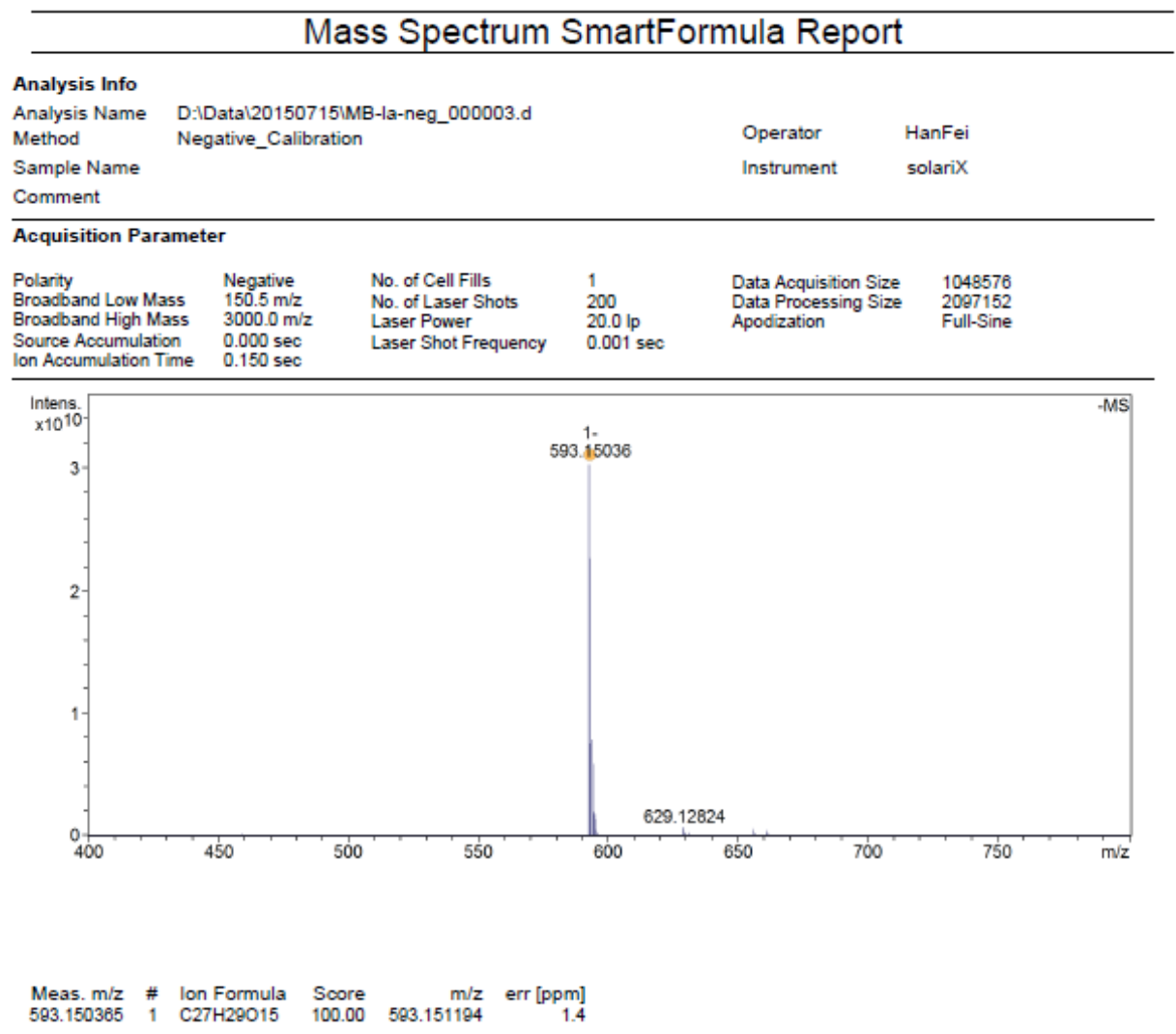

Figure S4. The ${ }^{1} \mathrm{H}-\mathrm{NMR}$ spectrum of compound $\mathbf{1}$

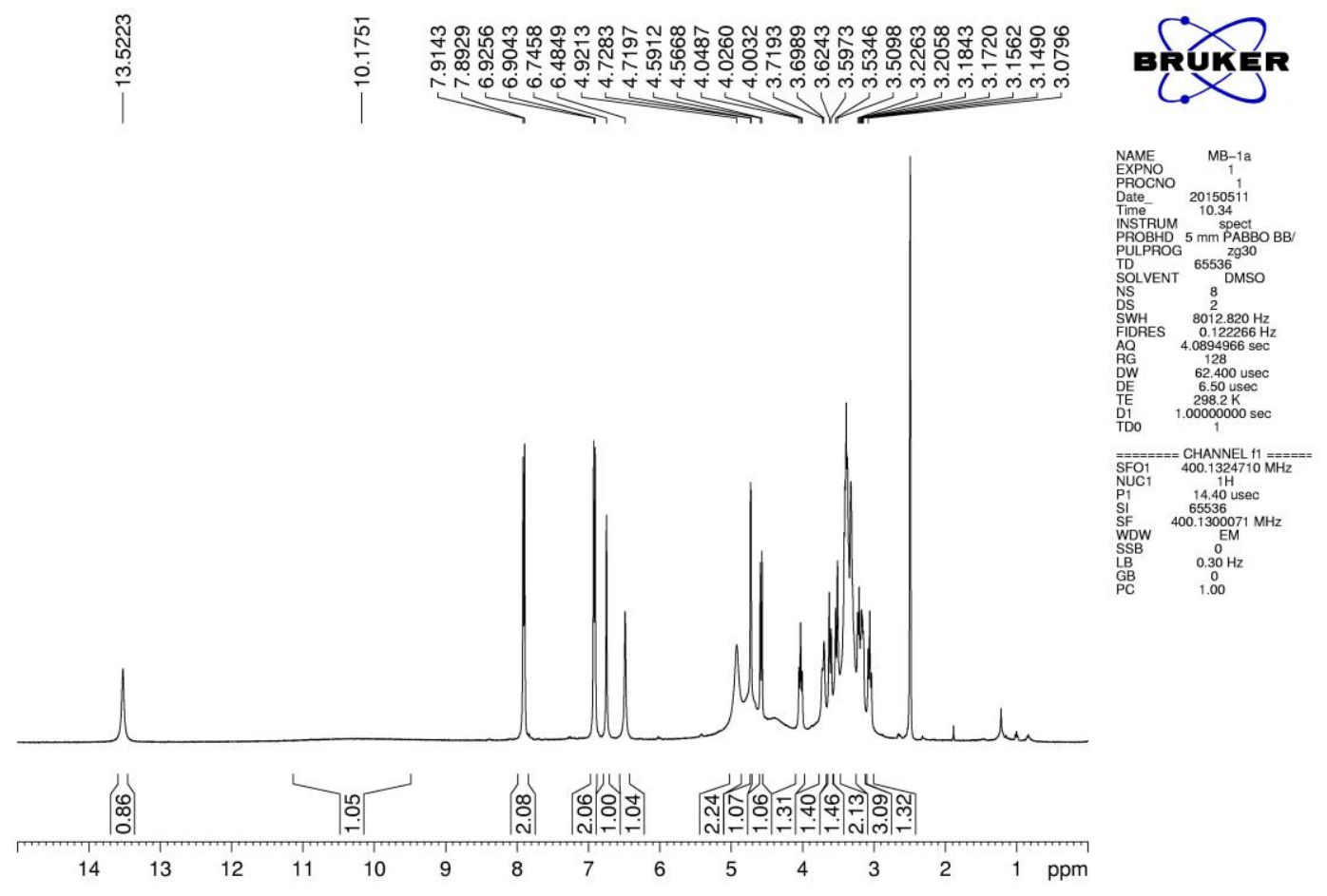


Figure S5. The ${ }^{13} \mathrm{C}-\mathrm{NMR}$ spectrum of compound $\mathbf{1}$

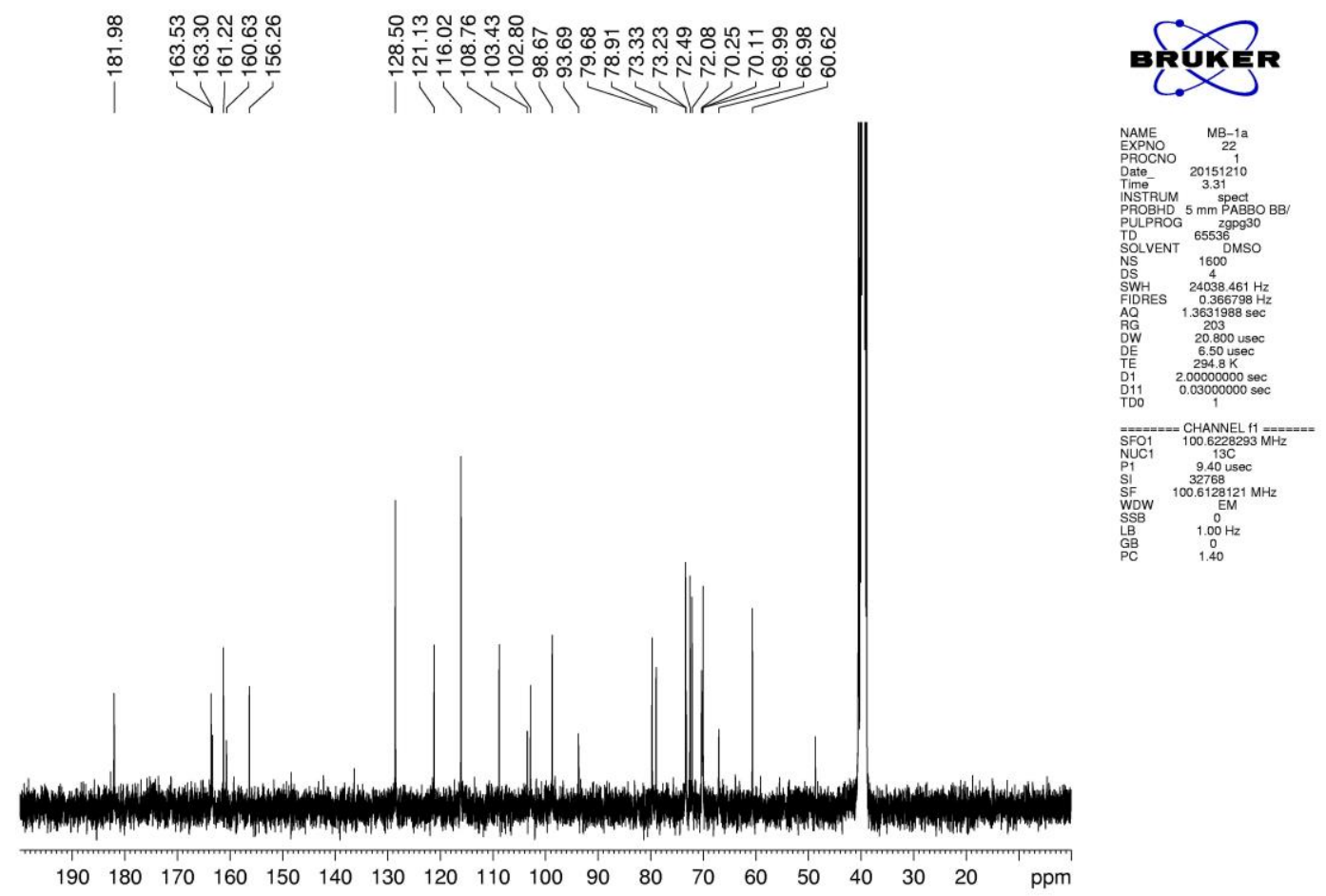

Figure S6. The HSQC spectrum of compound 1

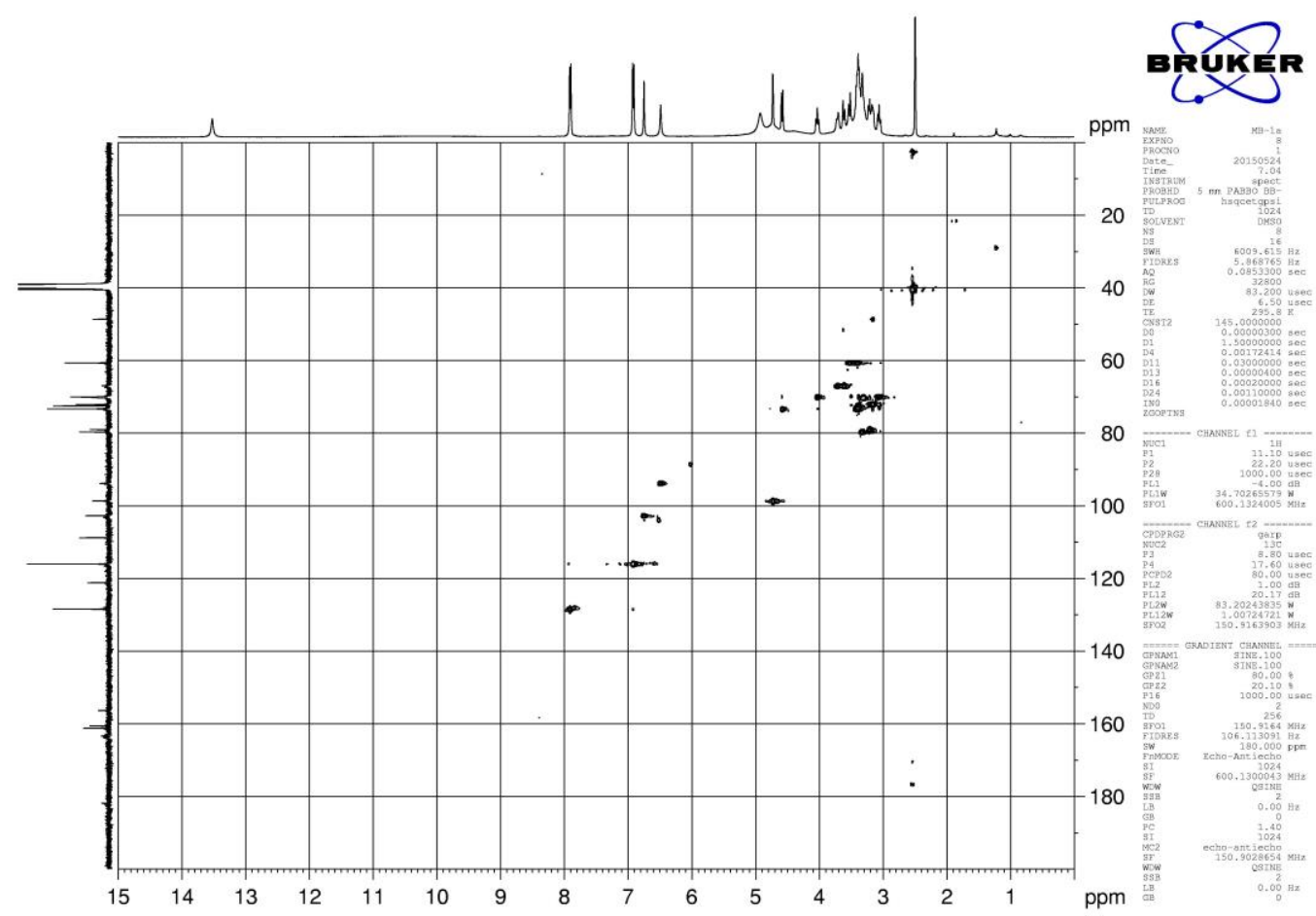


Figure S7. The HMBC spectrum of compound 1

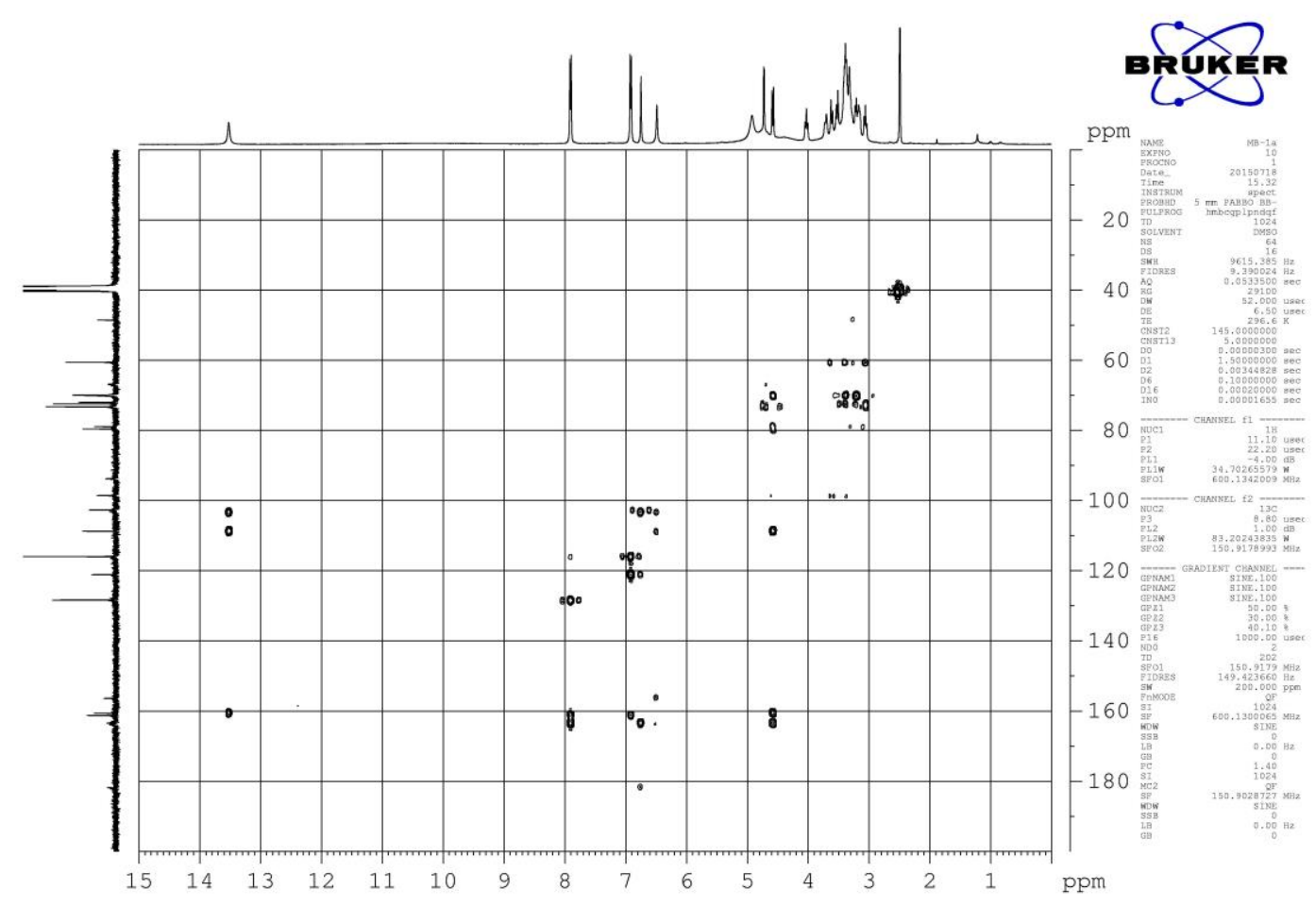

